\title{
Cancer Incidence in African Continent. Hands on to Produce more Information
}

\author{
Recueillir davantage de données pertinentes sur les cas de cancer en Afrique
}

\author{
M.P. Curado \\ C Springer-Verlag France 2014
}

\begin{abstract}
Africa is the third most populous continent in the world, with an estimated population of 1 billion people. The number of cancer cases has been estimated in approximately 850 thousand people in the African continent [1]. The most common cancers verified in women were breast, cervical, liver, and colorectal cancers. For men, the most common were prostate, liver, Kaposi sarcoma, and colorectal cancers [2]. This information was obtained from population-based cancer registries and death-certified data bases.
\end{abstract}

However, there are few cancer registries in the African continent that have produced continuous data throughout the last twenty years. One of the reasons is the obvious difficulty of the public health system to maintain cancer registries; current priorities in Africa include the availability of treatment, access to drugs, and existence of functional rehabilitation units.

In volume X of Cancer Incidence in Five Continents, cancer incidence data for the African population originated from eight population-based cancer registries (namely: Algeria, Setif; Egypt, Gharbiah; Libya, Benghazi; Malawi, Blantyre; South Africa, PROMEC; Tunisia, North; Uganda, Kyadondo county; and Zimbabwe, Harare). The total population coverage is approximately 18 million people, with data until 2007 -representing less than $0.18 \%$ of the African population. One of the required parameters for the International Agency for Research on Cancer (IARC) to publish cancer registry data is sufficient data quality. Of the aforementioned registries, three do not extract data from death certificates, and the proportion of microscopic verification by cancer site varies significantly (e.g., ranging between 0 and $90 \%$ for cervical cancer) [3].

The lack of reliable data on cancer is an indicator of the country's situation in terms of information, facilities for can- cer treatment, and human resources. The evaluation of quality control indicators can provide insights on local conditions for cancer diagnosis and care. Low data quality not only signals the absent collaboration between reporting sources and the inability of the registrar to perform quality abstracting, but also points to specific weaknesses of the cancer care system and can guide toward improvement goals and efforts [4]. It is evident that initiatives are needed to improve information on cancer in Africa.

A collaboration between the African Organisation for Research and Training in Cancer (AORTIC, a nongovernmental organization) and the IARC, through the Global Initiative for Cancer Registry Development (GICR), launched a program to improve population-based cancer registries in Africa. The GICR aims at placing cancer and its surveillance firmly on the emerging global Non-Communicable Diseases agenda, developing the capacity to produce reliable, highquality information on the burden of cancer so that effective policies for cancer control are developed, implemented, and evaluated [5].

The dissemination of research initiatives and results is being carried out through specific scientific journals for African researchers, such as the African Journal of Cancer. A bilingual journal can be a strong tool to support the dissemination of any cancer study conducted in Africa, and moreover, to support publications from the African cancer registries.

Finally, the improvement of cancer information depends primarily on the dissemination of the available data to the target population, aiming to create opportunities for discussion and improvement.

Conflict of interest: Author have no conflict of interest to declare.

\footnotetext{
M.P. Curado ( $\square)$

Senior Researche, International Prevention Research Institute (IPRI), 15, chemin du Saquin, espace Européen, F-69130 Ecully, France

e-mail : maria-paula.curado@i-pri.org
} 


\section{References}

1. United Nations Population Division, http://esa.un.org/unpd/wpp/ Excel-Data/population.htm, accessed on 19/01/2014

2. Ferlay J, Soerjomataram I, Ervik M, et al (2013) GLOBOCAN 2012 v1.0, Cancer Incidence and Mortality Worldwide: IARC Cancer Base No. 11 [Internet]. Lyon, France: International Agency for Research on Cancer. Available from: http://globocan.iarc.fr, accessed on 19/01/2014
3. Forman D, Bray F, Brewster DH, et al (eds) (2013) Cancer Incidence in Five Continents, Vol. X (electronic version), Lyon, IARC. http://ci5.iarc.fr, last accessed on 19/01/2014

4. Curado MP, Voti L, Sortino-Rachou AM (2009) Cancer registration data and quality indicators in low and middle income countries: their interpretation and potential use for the improvement of cancer care. Cancer Causes Control 20:751-6

5. Global initiative for cancer registry development-GICR, http:// gicr.iarc.fr/, accessed on 19/01/2014 